\title{
Associations of Body Mass Index with Demographics, Lifestyle, Food Intake, and Mental Health among Postpartum Women: A Structural Equation Approach
}

\author{
Hashem Salarzadeh Jenatabadi * ${ }^{D}$, Che Wan Jasimah Bt Wan Mohamed Radzi ${ }^{(D)}$ and \\ Nadia Samsudin (D) \\ Department of Science and Technology Studies, Faculty of Science, University of Malaya, Kuala Lumpur 50603, \\ Malaysia; jasimah@um.edu.my (C.W.J.B.W.M.R.); nadiasamz91@gmail.com (N.S.) \\ * Correspondence: jenatabadi@um.edu.my
}

Received: 14 May 2020; Accepted: 14 July 2020; Published: 18 July 2020

check for updates

\begin{abstract}
As postpartum obesity is becoming a global public health challenge, there is a need to apply postpartum obesity modeling to determine the indicators of postpartum obesity using an appropriate statistical technique. This research comprised two phases, namely: (i) development of a previously created postpartum obesity modeling; (ii) construction of a statistical comparison model and introduction of a better estimator for the research framework. The research model displayed the associations and interactions between the variables that were analyzed using the Structural Equation Modeling (SEM) method to determine the body mass index (BMI) levels related to postpartum obesity. The most significant correlations obtained were between BMI and other substantial variables in the SEM analysis. The research framework included two categories of data related to postpartum women: living in urban and rural areas in Iran. The SEM output with the Bayesian estimator was 81.1\%, with variations in the postpartum women's BMI, which is related to their demographics, lifestyle, food intake, and mental health. Meanwhile, the variation based on SEM with partial least squares estimator was equal to $70.2 \%$, and SEM with a maximum likelihood estimator was equal to $76.8 \%$. On the other hand, the output of the root mean square error (RMSE), mean absolute error (MSE) and mean absolute percentage error (MPE) for the Bayesian estimator is lower than the maximum likelihood and partial least square estimators. Thus, the predicted values of the SEM with Bayesian estimator are closer to the observed value compared to maximum likelihood and partial least square. In conclusion, the higher values of R-square and lower values of MPE, RMSE, and MSE will produce better goodness of fit for SEM with Bayesian estimators.
\end{abstract}

Keywords: body mass index; postpartum obesity; structural equation modeling

\section{Introduction}

High-income countries are often plagued with an obesity pandemic [1]. In that regard, the populations in low- and middle-income countries that are affected by obesity and overweight problems has also risen, especially in urbanized areas [2]. Today, newly emerging public health complications pertaining to women that can affect maternal and child outcomes are pre-pregnancy obesity, excessive gestational weight gain (GWG) [3], and postpartum weight retention (PPWR) [4]. Based on the world population in 2016, an estimated 2.1 billion people were found to be overweight, of which 650 million were obese [5]. It is predicted that half of the population will be affected by obesity and overweight by 2030 [6]. According to the WHO, worldwide obesity has nearly tripled since 1975 , with $39 \%$ of the adult population being overweight, and 13\% suffering from obesity [1].

Obesity can also damage health and reduced lifespan $[7,8]$. According to previous studies, people with an overweight problem often try to lose weight, but it seems that not many are successful at 
long-term weight loss maintenance [5]. Obesity could be a risk factor for cardiovascular disease because the accumulation of abdominal fat increases morbidity and mortality from related illnesses [9]. Based on WHO data, more women are reportedly overweight and obese than men [1]. Obesity is a threat to women during the antepartum, peripartum, and postpartum stages [10]. Hence, the world is facing another health issue that is associated with maternal obesity [11].

The pregnancy and postpartum periods are fragile phases for women when they experience weight gain and body structure changes [12]. During pregnancy, approximately $48 \%$ of women gain weight excessively [13]. Referring to the guidelines presented by the US Institute of Medicine (IOM), the gestational weight gain (GWG) of women with obesity should be 5.0-9.0 kg [14]. Unfortunately, $20-40 \%$ of pregnant women with obesity exceed the GWG recommended by IOM. Obesity in pregnancy might impact the health of both mother and infant in terms of diabetes, hypertensive disorders, preeclampsia, caesarean delivery, high birth weight, preterm delivery, late fetal loss and stillbirth $[15,16]$. High maternal BMI may lead to postpartum complications, such as continuous weight gain and increased risk of life-long obesity, metabolic syndrome, cardiovascular diseases, and Type 2 diabetes [10,17]. In the early period of postpartum, Butte et al. [18] claimed that the weight of lactating mothers showed a decreasing trend in the first four months postpartum. In order to produce more breast milk, mothers increase their daily diet incessantly, which happened to be one of the reasons postpartum women do not return to their pre-pregnancy weight in less than a year [19].

\subsection{Previous Studies in Postpartum Obesity Modelling}

Few research articles noted and clarified the indicators of obesity and overweight among postpartum women $[20,21]$, and we categorized them into four main groups of indicators related to demographics, food behaviour, health, and lifestyle. The next paragraphs explain how, in previous studies, it was mentioned that those variables were related to their BMI (as a representative of obesity).

The sociodemographic and economic situation are among the main factors that are significant for postpartum women obesity, which is confirmed from previous studies [22-24]. Age, education, income, and job experience are the most familiar variables that research scholars are concerned with. In our study, we considered the combination of them in one latent variable as the primary independent variable. Some researchers have found that physical function, sleep quality, average working hours per day, and smoking habits were affecting postpartum obesity. However, there is a lack of studies related to the impact of the average use of screen time on postpartum obesity. These factors represent their lifestyle. In most previous studies regarding postpartum obesity modelling, the effect of those factors on BMI was considered, separately. The factors are related to each other and could be considered as one of the groups of lifestyle variables and are defined as a latent variable. The indicators of lifestyle latent variable (research variable) depend on the participant's characteristics. The measurement of the variable is defined based on the postpartum lifestyle.

Previous studies like Garmendia et al. [25] reasserted that a factor contributing to women becoming overweight or obese during the postpartum period is an unhealthy lifestyle. Regarding the impact of an unhealthy lifestyle on the postpartum stage, some reviews have highlighted the link between women's sleep behaviour and physical activity. To emphasize this link, Wen et al. [26] claimed that poor sleep quality would lead women to do less exercise in the postpartum period. This claim was also supported by Waring et al. [27], who indicated that lack of exercise is one of the reasons postpartum women become obese. It is undeniable that some physical activity can prevent excessive gestational and postpartum weight gain [28-30]. Variables such as physical activity and sleep behaviour were considered in their research model. In this study, we added screen time, work amount, and smoking habit to the other variables (amount of sleep and physical activity), and they were considered as latent lifestyle variables.

Kay et al. [31] asserted that postpartum obesity is also a result of women's food consumption behaviour in terms of low consumption of fruits, vegetables, whole grains, and lean protein foods. Parallel to findings on women's food consumption behaviour, the intake of sugar-sweetened beverages 
has been linked to postpartum obesity as well. For instance, the findings from a quantitative-based study conducted by Harris et al. [32] showed that many postpartum women like to have sugar-sweetened beverages. These studies were in agreement with Kay et al. [31] regarding the high intake of sugar-sweetened beverages by postpartum women.

Mental disorders also appear to coincide with being overweight and suffering from obesity $[33,34]$. It is very common for postpartum women to be afflicted with mental disorders as well [35]. Yet studies on the relationship between obesity and mental health seem insufficient so far. Among the existing research on this topic, Teo et al. [36] investigated the correlation between mental health and food intake during the postpartum period, but the variables were not linked with BMI. Hence, limited evidence from previous studies focusing on mental health effects on postpartum obesity could be found.

\subsection{Aim of the Study and Research Framework}

The research framework of this study is the improvement of previous studies on postpartum obesity modelling, and we had involved other research variables obtained from previous literature related to adult and child obesity modelling. Demographics, food intake, and mental health are the most familiar variables in previous studies in postpartum obesity analysis, including the correlation between physical activities with food intake [37], food intake, and sleep quality [38], food intake and health [39]. Therefore, there were some existing studies about the correlation between the lifestyle variables (e.g., sleep quality and physical activity), food behaviour and health. These variables were held to be the most identifiable indicators in the postpartum obesity modelling literature. The elements of lifestyle are one of the leading research variables that are included in the obesity modelling. This was present in some of the previous studies related to children [40] and youth [41]. Those studies showed that the links between the demographics had allowed the BMI to be examined through lifestyle, food intake, and mental health. However, there is a lack of studies that investigate the factors affecting postpartum obesity and that combine the essential variables (lifestyle, food intake, and mental health), which all add to the complexity in acquiring the output of the postpartum women's BMI.

The first contribution of this study was to construct new relationships between the postpartum women's lifestyle, food behaviour, mental health, and BMI. These relationships were established after the demographics were examined in order to understand the impact of the alleged factors on postpartum obesity. Figure 1 illustrates the conceptual model framework for this research. The framework comprises demographics (initial independent variable), postpartum women's BMI (main dependent variable), and the remaining variables that function as mediators, known as endogenous and exogenous. The weight pre-pregnancy is added as the control variable, which is consistent with previous literature [42,43].

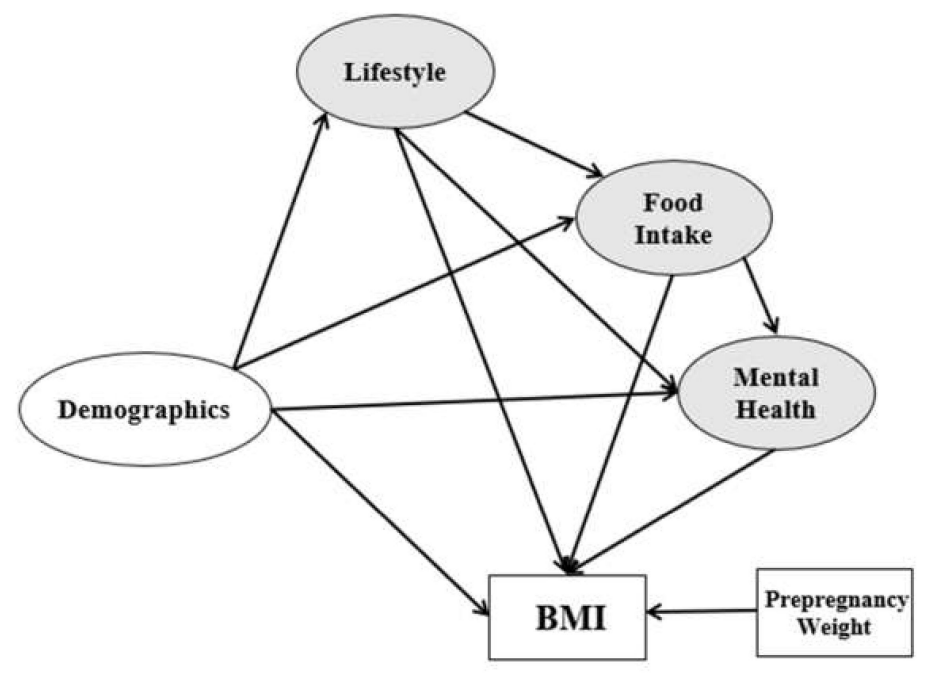

Figure 1. Research framework. 
The following Equations (1)-(4) show statistical regression modeling between the research variables:

$$
\begin{gathered}
\text { BMI }=\alpha_{1} \text { Demographics }+\alpha_{2} \text { Lifestyle }+\alpha_{3} \text { Food Intake }+\alpha_{4} \text { Mental Health } \\
+\alpha_{5} \text { Prepregnancy Weight } \\
\text { Mental Health }=\beta_{1} \text { Demographics }+\beta_{2} \text { Lifestyle }+\beta_{3} \text { Food Intake } \\
\text { Food Intake }=\gamma_{1} \text { Demographics }+\gamma_{2} \text { Lifestyle } \\
\text { Lifestyle }=\mu_{1} \text { Demographics }
\end{gathered}
$$

Obesity modeling with the application of SEM research has been a particular interest of researchers for the last few years. This method enables the estimation of BMI as the dependent variable based on the fundamental relationship between the observed and non-observed variables. Previous studies already introduced a few predictors or estimators for the SEM analysis. In related research on SEM analysis, the maximum likelihood is the most commonly used among all the estimators [44]. Nevertheless, the maximum likelihood estimator is frequently conceded by model misspecification. As an example, poor model fitting results may be produced from the models that are too strict with zero residual correlations and exact zero cross-loadings [45]. A maximum likelihood estimator has been proved by some researchers that demonstrates substantial parameter bias in factor loadings and factor correlation $[46,47]$. Some researchers already used alternative estimators in modeling to overcome the limitation of maximum likelihood in the SEM analysis due to the small sample size and normal distribution of independent variables. Thus, a few researchers have suggested applying the Bayesian method to overcome the limitations of the maximum likelihood method [44,48]. There seems to be a lack of comparative studies in the literature which examine the patterns that influence postpartum obesity and overweight problem using a multilevel framework that comprises different statistical modeling. Thus, a comparative analysis is currently one of the well-known statistical methods and introduce a better estimator in this dataset would be the second contribution of this study. This approach gives further knowledge about the Bayesian methods of predictive power and also offers opportunities to extend the research.

Several packages within the R language $[49,50]$ provide excellent open source tools for fitting the SEM, including lavaan [51] and OpenMX [52]. Nevertheless, proprietary SEM programs such as Amos [53], LISREL [54], and Mplus [55] enjoy widespread use for a variety of reasons, including ease of use, specialized modeling facilities, and users' familiarity.

Therefore, the main objective of this study includes two parts. The first part is to explore and develop the previous modeling in postpartum obesity. The second part is to do statistical comparison modeling and introduce a better estimator for the research framework, which is presented in Figure 1.

\section{Materials and Methods}

\subsection{Sampling}

The cross-sectional study design was applied in this research. Accordingly, the data was collected from the research population sample at only one point in time. The researchers had various notions of the sample size. For example, Hair et al. [56] in the theory of structural equation modeling indicated that the sample size is supposed to be related to the number of latent variables in the study, which includes the number of indicators within the latent variables. Table 1 presents Hair et al.'s [56] scheme for choosing the sample size. 
Table 1. Minimum sample size in SEM analysis.

\begin{tabular}{cl}
\hline Sample Size Required & \multicolumn{1}{c}{ Criteria from the Research Model } \\
\hline 100 participants & $\begin{array}{l}\text { Consists of five or less latent variables, each of which has at least three indicators } \\
\text { Consists of seven or less latent variables, each of which has at least } \\
\text { three indicators }\end{array}$ \\
150 participants & $\begin{array}{l}\text { Consists of seven or less latent variables, each of which has less than } \\
\text { three indicators } \\
300 \text { participants }\end{array}$ \\
500 participants & $\begin{array}{l}\text { Consists of more than seven latent variables, each of which has less than } \\
\text { three indicators }\end{array}$ \\
\hline
\end{tabular}

For this study, women who were within one year after giving birth were surveyed. We recognized the one-year postpartum period would be a proper time as women usually recover from childbirth, which corresponds to previous studies [57,58]. The respondents were selected randomly from governmental healthcare centres using proportionate stratified random sampling. The survey was conducted with funding from the University of Malaya (project number GPF066B-2018) and approved by the University of Malaya Research Ethics Committee (UM.TNC2/RC/H\&E/UMREC 127). The research methods were performed in accordance with the relevant guidelines and regulations. The respondents were provided with an explanation of the research purpose, and informed consent was obtained from all the respondents.

This research considered both urban and rural areas. The main reason the rural and the urban area were chosen was that both areas have different lifestyles and different facilities. Therefore, we preferred to conduct a comparative analysis between the rural and the urban area to understand the significant variables which are effective on BMI. Five main cities of Iran were chosen for the data collection area. Those cities were Tehran, Mashhad, Isfahan, Shiraz, and Tabriz that have the highest population in Iran. For every city, we considered 80 questionnaires for the urban and 30 questionnaires for the rural area. Questionnaires were distributed in some clinics that had agreed to cooperate in this research. From the 550 distributed questionnaires (400 in urban areas and 150 in rural areas), 480 were returned (359 for urban and 121 for rural). The rest refused to participate. From the 480 questionnaires, 28 were eliminated due to missing data (19 urban and nine rural participants). Sixteen (16) bachelor and master students of public health and management were trained for the data collection phase.

The postpartum period considered was one year, and maybe the first one may be varied with respect to the twelfth month. To avoid this issue, we applied an outlier analysis at this point in the study. The Mahalanobis distance is a familiar technique for recognizing outliers in SEM [59]. The Mahalanobis distance output signified that nine observations were outliers, which were consequently eliminated from the data analysis. Therefore, $(480-28-9=443) 443$ observations were considered as the final sample size for this study.

\subsection{Research Variable Measurement}

We measured every latent variable based on previous studies and adjusted them based on Iran currency and postpartum situation [60].

\subsubsection{Demographics (Independent Variable)}

Three main measurements were considered for the demographics of the postpartum women: age and work experience. We measured this variable based on previous studies [61-63]. Age was classified into five groups, which were below 21, 21 to 25, 26 to 30, 31 to 35, and over 35 years old. Educational background was categorized as less than high school, high school, diploma, Bachelor, and Master or $\mathrm{PhD}$. The respondents' work experience was categorized according to no job experience, 1 to 3 years, 4 to 6 years, 7 to 10 years, and more than 10 years. The last question in the socio-demographics part was related to household income per month, and the responses were grouped according to less than 2 MT, 2 to 3 MT, 3 to 4 MT, 4 to 5 MT, and over 5 MT (MT: Million Tomans). The results suggest 
a good fit of specification $\left\{\left[\chi^{2}\right]=55.21,[C F I]=0.909,[N F I]=0.959,[T L I]=0.944,[R F I]=0.931\right.$, $[\mathrm{GFI}]=0.908$, and $[\mathrm{RMSEA}]=0.049\}$. The value of RMSEA is below 0.050. CFI, NFI, TLI, RFI, and GFI all exceed the recommended threshold level of 0.90 [64]. As a result, demographic measurement model is well-defined.

\subsubsection{Lifestyle (First Mediator)}

According to Nakayama et al. [65], lifestyle encompasses the average working hours, physical activity, smoking habit, and average sleep hours, which were used in the present study as well. Melzer et al. [66] claimed that smoking habits and physical activity, in particular, are predictors of postpartum obesity. In the current study, one more element was added to the postpartum women's lifestyle, namely the average hours of screen time (e.g., TV, smartphone, tablet, etc.) to measure the respondents' social media use [67-69]. For measuring average screen time, we asked three questions. These questions: 'During the past 7 days, how many hours/per day did you watch TV?', 'During the past 7 days, how many hours/per day did you spend using a laptop/or computer for watching movies, e-mailing, playing games, etc.?', and During the past 7 days, how many hours/per day did you spend using a handphone for watching movies, e-mailing, playing games, using (WhatsApp, Facebook, Instagram, etc.), etc.?' Based on those three questions we calculated the average screen time based on five categories: less than $1 \mathrm{~h}, 1$ to $2 \mathrm{~h}, 2$ to $3 \mathrm{~h}, 3$ to $4 \mathrm{~h}$, and more than $4 \mathrm{~h}$. The responses for the average working hours per day were in five categories denoted by none, less than $7 \mathrm{~h}, 7$ to $8 \mathrm{~h}, 8$ to $9 \mathrm{~h}$, and more than $9 \mathrm{~h}$. Regarding physical activity, we asked two questions. These questions were: “During the past 7 days, on how many days did you participate in at least $60 \mathrm{~min}$ per day of any kind of physical activity that increased your heart rate and made you breath hard, such as fast bicycling, kicking shuttlecock, or aerobic activities, etc.?" and "During the past 7 days, on how many days did you do exercises to strengthen or tone your muscles, such as push-ups, sit-ups, weight lifting, etc.?" [70].

Based on those two questions, we calculated the frequency of physical activity into six categories: none, 1 day, 2 days, 3 days, 4 days, and more than 4 days. Smoking habit was categorized as non-smoker, quit, 1 to 3 cigarettes per day, 4 to 6 cigarettes per day, 7 to 10 cigarettes per day, and more than 10 cigarettes per day. However, in data analysis, the respondents who smoke were grouped as smokers. The average hours of sleep per day were indicated as less than $6 \mathrm{~h}, 6$ to $7 \mathrm{~h}, 7$ to $8 \mathrm{~h}, 8$ to $9 \mathrm{~h}$, and more than $9 \mathrm{~h}$. The results suggest a good fit of specification $\left\{\left[\chi^{2}\right]=48.66,[\mathrm{CFI}]=0.906,[\mathrm{NFI}]=0.933\right.$, $[\mathrm{TLI}]=0.918,[\mathrm{RFI}]=0.976$, [GFI $]=0.938$, and $[$ RMSEA $]=0.037\}$. The value of RMSEA is below 0.050 . CFI, NFI, TLI, RFI, and GFI all exceed the recommended threshold level of 0.90 [64]. As a result, lifestyle measurement model is well-defined.

\subsubsection{Food Intake (Second Mediator)}

There are a few theories for measuring food intake (or food consumption). We combined two theories [71,72] to measure food intake in this study. Information on food intake was collected with $24 \mathrm{~h}$ recall from all participants. Nine indicators used for the food intake variables were considered. These included whole grains (grams/day), fruits (grams/day), vegetables (grams/day), sweets (grams/day), chips (grams/day), soft drinks (millilitre/day), fast food (grams/day), processed food (serves/week), Non-processed food (serves/week). For primary measurement analysis, the results did have a good fit of specification $\left\{\left[\chi^{2}\right]=12.66,[\mathrm{CFI}]=0.806,[\mathrm{NFI}]=0.833,[\mathrm{TLI}]=0.918,[\mathrm{RFI}]=0.976\right.$, $[\mathrm{GFI}]=0.938$, and $[$ RMSEA $]=0.089\}$. Therefore, we applied modification indices for this part of our study. After modification, almost all indices increased and meet the criteria $\left\{\left[\chi^{2}\right]=21.03\right.$, $[\mathrm{CFI}]=0.921$, $[\mathrm{NFI}]=0.909,[\mathrm{TLI}]=0.925,[\mathrm{RFI}]=0.982,[\mathrm{GFI}]=0.955$, and $[\mathrm{RMSEA}]=0.037\}$.

\subsubsection{Mental Health (Third Mediator)}

The next latent variable (third mediator) is mental health. Based on Nakayama et al. [65] and Boardman [73] studies, they had proposed these indicators to measure mental health i.e., the serious problems that were faced, stress levels, and happiness in life. These indicators should be determined 
according to the previous year of the mental state. We chose to use these two theories as this study is measuring mental health generally without medical intervention. This latent variable is been used for the first time to measure the impact of this latent variable on postpartum obesity modeling. Mental health has been used in previous studies but in a different context [41,62]. Yet, there is a lack of studies in postpartum obesity modeling that used mental health as a latent variable.

In this study, the problems they faced were grouped into three categories: no serious problems, 1 or 2 serious problems, and more than two serious problems. Responses to the stress levels were indicated by the normal, medium, and high levels of stress. Happiness in life was categorized as not happy, average, and happy. The results suggest a good fit of specification $\left\{\left[\chi^{2}\right]=38.98,[C F I]=0.939\right.$, $[\mathrm{NFI}]=0.943,[\mathrm{TLI}]=0.918,[\mathrm{RFI}]=0.977,[\mathrm{GFI}]=0.952$, and $[\mathrm{RMSEA}]=0.046\}$. The value of RMSEA is below 0.050. CFI, NFI, TLI, RFI, and GFI all exceed the recommended threshold level of 0.90 [64]). As a result, mental health measurement model is well-defined.

\subsubsection{BMI (Dependent Variable)}

To measure the BMI of an individual, the weight and height indicators need to be calculated as follows [74]:

$$
\mathrm{BMI}=\frac{(\text { Weight in kilograms })}{{\text { (Height in meters })^{2}}^{2}}
$$

For postpartum women, the BMI was determined according to standard measurement [75]. In this study on postpartum obesity, Table 2 serves as a reference for BMI measurement.

Table 2. BMI categories.

\begin{tabular}{cc}
\hline BMI $\left(\mathbf{k g} / \mathbf{m}^{\mathbf{2}}\right)$ & Category \\
\hline$<18.5$ & Underweight \\
$18.5-24.9$ & Normal \\
$25.0-29.9$ & Overweight \\
$\geq 30.0$ & Obese \\
\hline
\end{tabular}

Postpartum women need to know their weight and height to enable for their BMI to be determined. Thus, with knowledge of the postpartum women's BMI, it was possible to clearly show the interconnections between latent and observable variables in this research.

\subsection{Statistical Method}

To aim is to analyze the relationship between numerous factors and BMI in postpartum obesity analysis, descriptive statistics, regression, MANOVA, and ANOVA, which are the most well-known applications used from a mathematical and statistical modeling point of view.

SEM is beneficial in this research for providing a better understanding of the concept of latent variables with their functions within the model. In other words, the ability to use latent variables. According to Bollen [76], "latent variables provide a degree of abstraction that permits us to describe relations among a class of events or variables that share something in common." A precise typical of SEM is the usage of 'latent variables,' which are not applied in any other statistical modeling. Latent variables refer to constructs that are not directly observable. For instance, in this study, lifestyle is regarded as a latent variable, which is defined as a combination (average or sum) of observed variables including physical activity, smoking habit, and average sleep hours as well as screen time.

\subsection{Data Analysis Software}

Analyses were performed using SPSS (version 25, SPSS Inc., Chicago, IL, USA) in the first part of data analysis, i.e., descriptive statistics analysis. While the AMOS software (IBM, Armonk, NY, USA) was applied in the second part of data analysis for the structural equation modeling analysis. 


\section{Results}

\subsection{Descriptive Analysis}

Table 3 shows the distribution of the respondents based on location. The majority of urban respondents are diploma holders, whereas most rural respondents only have a high school education. For the highest monthly income, $38.2 \%$ of urban respondents receive $4-5$ MT per month, and $60.2 \%$ of the rural respondents receive 2-3 MT per month. The smallest number of rural respondents have no job experience, and none has ever worked for more than 10 years. Many urban and rural respondents have worked for 4-6 years and 1-3 years, respectively. Besides, 25.7\% of the study sample from the urban regions participate in physical activity 3 times a week, but $38.9 \%$ of the rural participants report that they take part in physical activity only once a week. The highest screen time per day for the urban sample is $44.5 \%$, and for the rural sample, their screen time is $58.3 \%$, which translates into $2-3$ and $1-2 \mathrm{~h}$ a day, respectively. As for sleep, most participants from the urban and rural areas sleep respectively around $7-8$ and less than $6 \mathrm{~h}$ per day. Yet the majority (63.3\%) of the urban postpartum women work $8-9 \mathrm{~h}$ a day, and $54.6 \%$ of the rural postpartum women work more than $9 \mathrm{~h}$ a day. It was also found that $51.6 \%$ of the urban participants are smokers, and $78.7 \%$ of the rural participants are non-smokers. Based on Table 3, 7.8\% of the respondents (26/335) from the urban study sample are underweight, $22.7 \%(76 / 335)$ are in the normal range, 55.2\% (185/335) are overweight, and $14.3 \%(48 / 335)$ suffer from obesity. In rural areas, $11.1 \%(12 / 108)$ of the respondents are underweight, $47.2 \%(51 / 108)$ are in the normal range, $30.6 \%(33 / 108)$ are overweight, and 11.1\% (12/108) have obesity.

The data were collected in the urban and rural areas in Iran via questionnaires that were distributed to a total of 335 urban participants and 108 rural participants, with no missing data. Thus, the data for this study were tabulated in the descriptive statistical analysis.

Table 3. Demographics, lifestyle, mental health, and BMI of respondents by area.

\begin{tabular}{|c|c|c|c|c|c|c|}
\hline & \multicolumn{3}{|c|}{ Number } & \multicolumn{3}{|c|}{ Percentage } \\
\hline & Total & Urban & Rural & Total & Urban & Rural \\
\hline \multicolumn{7}{|c|}{ Age $(n, \%)$} \\
\hline 21 to 25 years old & 30 & 21 & 9 & $6.8 \%$ & $6.3 \%$ & $8.3 \%$ \\
\hline 26 to 30 years old & 99 & 74 & 25 & $22.3 \%$ & $22.1 \%$ & $23.1 \%$ \\
\hline 31 to 35 years old & 173 & 132 & 41 & $39.1 \%$ & 39.4 & $38.0 \%$ \\
\hline Over 35 years old & 141 & 108 & 33 & $32.2 \%$ & $32.2 \%$ & $30.6 \%$ \\
\hline \multicolumn{7}{|c|}{ Education $(\mathrm{n}, \%)$} \\
\hline Less than high school & 26 & 5 & 21 & $5.9 \%$ & $1.5 \%$ & $19.4 \%$ \\
\hline High school & 119 & 75 & 44 & $26.9 \%$ & $22.4 \%$ & $40.7 \%$ \\
\hline Diploma & 151 & 124 & 27 & $34.1 \%$ & $37.0 \%$ & $25.0 \%$ \\
\hline Bachelor & 101 & 89 & 12 & $22.8 \%$ & $26.6 \%$ & $11.1 \%$ \\
\hline Master or PhD & 46 & 42 & 4 & $10.4 \%$ & $12.5 \%$ & $3.7 \%$ \\
\hline \multicolumn{7}{|c|}{ Income $(\mathrm{n}, \%)$} \\
\hline$<2 \mathrm{MT}(\$ 200)$ & 80 & 43 & 37 & $18.1 \%$ & $12.8 \%$ & $34.3 \%$ \\
\hline 2-3 MT (\$200-300) & 111 & 46 & 65 & $25.1 \%$ & $13.7 \%$ & $60.2 \%$ \\
\hline 3-4 MT (\$300-400) & 81 & 76 & 5 & $18.3 \%$ & $22.7 \%$ & $4.6 \%$ \\
\hline $4-5$ MT $(\$ 400-500)$ & 129 & 128 & 1 & $29.1 \%$ & $38.2 \%$ & $0.9 \%$ \\
\hline$>5 \mathrm{MT}(\$ 500)$ & 42 & 42 & 0 & $9.5 \%$ & $12.5 \%$ & $0.0 \%$ \\
\hline \multicolumn{7}{|c|}{ Job Experience (n, \%) } \\
\hline No job experience & 58 & 26 & 32 & $13.1 \%$ & $7.8 \%$ & $29.6 \%$ \\
\hline $1-3$ years & 111 & 62 & 49 & $25.1 \%$ & $18.5 \%$ & $45.4 \%$ \\
\hline $4-6$ years & 191 & 166 & 25 & $43.1 \%$ & $49.6 \%$ & $23.1 \%$ \\
\hline $7-10$ years & 53 & 51 & 2 & $12.0 \%$ & $15.2 \%$ & $1.9 \%$ \\
\hline$>10$ years & 30 & 30 & 0 & $6.8 \%$ & $9.0 \%$ & $0.0 \%$ \\
\hline
\end{tabular}


Table 3. Cont.

\begin{tabular}{|c|c|c|c|c|c|c|}
\hline & \multicolumn{3}{|c|}{ Number } & \multicolumn{3}{|c|}{ Percentage } \\
\hline & Total & Urban & Rural & Total & Urban & Rural \\
\hline \multicolumn{7}{|c|}{ Physical Activity (n, \%) } \\
\hline None & 105 & 71 & 34 & $23.7 \%$ & $21.2 \%$ & $31.5 \%$ \\
\hline 1 day/week & 105 & 63 & 42 & $23.7 \%$ & $18.8 \%$ & $38.9 \%$ \\
\hline 2 days/week & 99 & 67 & 32 & $22.3 \%$ & $20.0 \%$ & $29.6 \%$ \\
\hline 3 days/week & 86 & 86 & 0 & $19.4 \%$ & $25.7 \%$ & $0.0 \%$ \\
\hline 4 days/week & 36 & 36 & 0 & $8.1 \%$ & $10.7 \%$ & $0.0 \%$ \\
\hline$>4$ days/week & 12 & 12 & 0 & $2.7 \%$ & $3.6 \%$ & $0.0 \%$ \\
\hline \multicolumn{7}{|c|}{ Screen Time (n, \%) } \\
\hline$<1 \mathrm{~h} /$ day & 40 & 16 & 24 & $9.0 \%$ & $4.8 \%$ & $22.2 \%$ \\
\hline 1-2 h/day & 104 & 41 & 63 & $23.5 \%$ & $12.2 \%$ & $58.3 \%$ \\
\hline $2-3 \mathrm{~h} /$ day & 170 & 149 & 21 & $38.4 \%$ & $44.5 \%$ & $19.4 \%$ \\
\hline 3-4 h/day & 88 & 88 & 0 & $19.9 \%$ & $26.3 \%$ & $0.0 \%$ \\
\hline$>4$ h/day & 41 & 41 & 0 & $9.3 \%$ & $12.2 \%$ & $0.0 \%$ \\
\hline \multicolumn{7}{|c|}{ Sleep $(n, \%)$} \\
\hline$<6$ h/day & 64 & 3 & 61 & $14.4 \%$ & $0.9 \%$ & $56.5 \%$ \\
\hline 6-7 h/day & 75 & 36 & 39 & $16.9 \%$ & $10.7 \%$ & $36.1 \%$ \\
\hline 7-8 h/day & 200 & 192 & 8 & $45.1 \%$ & $57.3 \%$ & $7.4 \%$ \\
\hline 8-9 h/day & 49 & 49 & 0 & $11.1 \%$ & $14.6 \%$ & $0.0 \%$ \\
\hline$>9$ h/day & 55 & 55 & 0 & $12.4 \%$ & $16.4 \%$ & $0.0 \%$ \\
\hline \multicolumn{7}{|c|}{ Work (n, \%) } \\
\hline None & 35 & 33 & 2 & $7.9 \%$ & $9.9 \%$ & $1.9 \%$ \\
\hline$<7$ h/day & 25 & 19 & 6 & $5.6 \%$ & $5.7 \%$ & $5.6 \%$ \\
\hline 7-8 h/day & 48 & 36 & 12 & $10.8 \%$ & $10.7 \%$ & $11.1 \%$ \\
\hline 8-9 h/day & 241 & 212 & 29 & $54.4 \%$ & $63.3 \%$ & $26.9 \%$ \\
\hline$>9$ h/day & 94 & 35 & 59 & $21.2 \%$ & $10.4 \%$ & $54.6 \%$ \\
\hline \multicolumn{7}{|c|}{ Smoking habit (n, \%) } \\
\hline Non-smoker & 193 & 108 & 85 & $43.6 \%$ & $32.2 \%$ & $78.7 \%$ \\
\hline Quit & 64 & 54 & 10 & $14.4 \%$ & $16.1 \%$ & $9.3 \%$ \\
\hline Smoker & 186 & 173 & 13 & $42.0 \%$ & $51.6 \%$ & $12.0 \%$ \\
\hline \multicolumn{7}{|c|}{ Serious problem $(\mathrm{n}, \%)$} \\
\hline 0 & 125 & 92 & 33 & $28.2 \%$ & $27.5 \%$ & $30.6 \%$ \\
\hline $1-2$ & 134 & 105 & 29 & $30.2 \%$ & $31.3 \%$ & $26.9 \%$ \\
\hline$>2$ & 184 & 138 & 46 & $41.5 \%$ & $41.2 \%$ & $42.6 \%$ \\
\hline \multicolumn{7}{|c|}{ Stress $(n, \%)$} \\
\hline Normal & 109 & 88 & 21 & $24.6 \%$ & $26.3 \%$ & $19.4 \%$ \\
\hline Medium & 118 & 86 & 32 & $26.6 \%$ & $25.7 \%$ & $29.6 \%$ \\
\hline High & 216 & 161 & 55 & $48.8 \%$ & $48.1 \%$ & $50.9 \%$ \\
\hline \multicolumn{7}{|c|}{ Happiness (n, \%) } \\
\hline Happy & 214 & 162 & 52 & $48.3 \%$ & $48.4 \%$ & $48.1 \%$ \\
\hline Average & 173 & 133 & 40 & $39.1 \%$ & $39.7 \%$ & $37.0 \%$ \\
\hline Not happy & 56 & 40 & 16 & $12.6 \%$ & $11.9 \%$ & $14.8 \%$ \\
\hline \multicolumn{7}{|c|}{ BMI $\left(\mathrm{kg} / \mathrm{m}^{2}\right)$} \\
\hline Underweight (n, \%) & 38 & 26 & 12 & $8.6 \%$ & $7.8 \%$ & $11.1 \%$ \\
\hline Normal (n, \%) & 127 & 76 & 51 & $28.7 \%$ & $22.7 \%$ & $47.2 \%$ \\
\hline Overweight (n, \%) & 218 & 185 & 33 & $49.2 \%$ & $55.2 \%$ & $30.6 \%$ \\
\hline Obese $(\mathrm{n}, \%)$ & 60 & 48 & 12 & $13.5 \%$ & $14.3 \%$ & $11.1 \%$ \\
\hline
\end{tabular}

The distribution of different types of food intake is presented in Table 4. Whole grains (bread, rice, pasta, noodles, breakfast cereals) among the urban sample are equal to $246.22 \pm 83.69 \mathrm{~g}$ per day. As for the rural sample it is equal to $241.34 \pm 89.56 \mathrm{~g}$ per day. 
Table 4. Descriptive statistics of food intake (Mean \pm Std).

\begin{tabular}{lcc}
\hline Whole Grains (g/day) & $246.22 \pm 83.69$ & $241.34 \pm 89.56$ \\
Fruits (g/day) & $392.11 \pm 120.49$ & $402.20 \pm 118.43$ \\
Vegetables (g/day) & $323.94 \pm 99.38$ & $328.88 \pm 93.80$ \\
Sweets (g/day) & $130.79 \pm 29.25$ & $126.56 \pm 29.03$ \\
Chips (g/day) & $90.96 \pm 34.98$ & $86.82 \pm 35.36$ \\
Soft Drinks (ml/day) & $385.53 \pm 129.80$ & $362.35 \pm 130.69$ \\
Fast Food (g/day) & $213.99 \pm 96.81$ & $196.37 \pm 99.33$ \\
Processed Food (serves/week) & $4.50 \pm 2.17$ & $3.81 \pm 1.93$ \\
Non-Processed Food (serves/week) & $2.52 \pm 1.74$ & $2.31 \pm 1.62$ \\
\hline
\end{tabular}

\subsection{SEM Analysis}

\subsubsection{Validity and Reliability}

The validity and reliability of a questionnaire are dependent on some conditions of SEM analysis based on Fornell et al. [77]:

(a) Validity:

i. The Cronbach's alpha value must be equal to or higher than 0.7 for every latent variable in the study.

(b) Reliability:

i. The factor loading of the indicator on each latent variable should be higher than 0.70 .

ii. The average variance extracted (AVE) for all the latent variables should be equal to or higher than 0.50 .

Table 5 tabulates the factor loading, AVE, and Cronbach's alpha of the demographics, lifestyle, food intake, and mental health variables. The table denotes that age, work, and vegetables obtained factor loading values of below 0.7. These indicators should therefore be excluded from the SEM analysis. However, we are supposed to apply moderation analysis to the comparison analysis between the urban and rural variables. Therefore, for better accuracy, we keep all of the indicators for the next level of SEM analysis. The Average Variance Extracted (AVE) analysis output is illustrated in Table 5, which demonstrates that all the latent variables' AVE values are greater than 0.5 . Since the reliability conditions are fulfilled, the study is accepted. Moreover, Table 5 displays the Cronbach's alpha output with four latent variables whose indices are higher than 0.7. According to the validity conditions applicable to the analysis, the research model is accepted.

Table 5. Validity and reliability output.

\begin{tabular}{|c|c|c|c|}
\hline Parameter Description & Urban & Rural & Total \\
\hline \multicolumn{4}{|c|}{ Demographics $(\mathrm{AVE}=0.51 ;$ Cronbach's Alpha $=0.72)$} \\
\hline Age & 0.43 & 0.56 & 0.51 \\
\hline Education & 0.81 & 0.62 & 0.76 \\
\hline Income & 0.76 & 0.73 & 0.73 \\
\hline Job Experience & 0.79 & 0.71 & 0.75 \\
\hline \multicolumn{4}{|c|}{ Lifestyle $(\mathrm{AVE}=0.53 ;$ Cronbach's Alpha $=0.73)$} \\
\hline Physical Activity & 0.73 & 0.53 & 0.77 \\
\hline Screen Time & 0.86 & 0.49 & 0.81 \\
\hline Sleep & 0.74 & 0.86 & 0.73 \\
\hline Work & 0.62 & 0.79 & 0.59 \\
\hline Smoking habit & 0.71 & 0.52 & 0.79 \\
\hline
\end{tabular}


Table 5. Cont.

\begin{tabular}{cccc}
\hline Parameter Description & Urban & Rural & Total \\
\hline Food Intake (AVE = 0.69; & Cronbach's Alpha & $\mathbf{0 . 7 7 )}$ & \\
\hline Whole Grains (g/day) & 0.56 & 0.73 & 0.71 \\
Fruits (g/day) & 0.72 & 0.83 & 0.81 \\
Vegetables (g/day) & 0.67 & 0.81 & 0.62 \\
Sweets (g/day) & 0.85 & 0.72 & 0.77 \\
Chips (g/day) & 0.88 & 0.61 & 0.79 \\
Soft Drinks (ml/day) & 0.92 & 0.59 & 0.88 \\
Fast Food (g/day) & 0.81 & 0.54 & 0.85 \\
Processed Food (servs/week) & 0.81 & 0.82 & 0.88 \\
Non-Processed Food & 0.78 & 0.71 & 0.76 \\
(servs/week) & & & \\
\hline Mental Health (AVE = 0.55; Cronbach's Alpha & $\mathbf{0 . 7 1 )}$ & \\
\hline Stress Level & 0.86 & 0.71 & 0.88 \\
Happiness & 0.84 & 0.72 & 0.89 \\
Problems & 0.88 & 0.66 & 0.86 \\
\hline
\end{tabular}

\subsubsection{Normality Testing}

We considered Anderson-Darling and Shapiro-Wilk statistics for the normality test. All of their $p$-values are less than 0.05 , and the normality of the variables is rejected Therefore, SEM with maximum likelihood estimator is not suitable for the modelling of our data (see Table 6).

Table 6. Normality Test.

\begin{tabular}{lcccc}
\hline \multirow{2}{*}{ Variables } & \multicolumn{2}{c}{ Anderson-Darling Test } & \multicolumn{2}{c}{ Shapiro-Wilk Test } \\
\cline { 2 - 5 } & Statistic & $p$-value & Statistic & $p$-value \\
\hline Age & 26.053 & $<0.001$ & 0.850 & $<0.001$ \\
Education & 16.503 & $<0.001$ & 0.911 & $<0.001$ \\
Income & 17.301 & $<0.001$ & 0.895 & $<0.001$ \\
Job Experience & 15.315 & $<0.001$ & 0.904 & $<0.001$ \\
Physical Activity & 13.980 & $<0.001$ & 0.907 & $<0.001$ \\
Screen Time & 16.011 & $<0.001$ & 0.913 & $<0.001$ \\
Sleep & 20.261 & $<0.001$ & 0.889 & $<0.001$ \\
Work & 40.276 & $<0.001$ & 0.783 & $<0.001$ \\
Smoking habit & 54.045 & $<0.001$ & 0.719 & $<0.001$ \\
Whole Grains (g/day) & 6.964 & $<0.001$ & 0.943 & $<0.001$ \\
Fruits (g/day) & 6.413 & $<0.001$ & 0.946 & $<0.001$ \\
Vegetables (g/day) & 4.374 & $<0.001$ & 0.959 & $<0.009$ \\
Sweets (g/day) & 5.220 & $<0.001$ & 0.953 & $<0.005$ \\
Chips (g/day) & 5.822 & $<0.001$ & 0.950 & $<0.001$ \\
Soft Drinks (mL/day) & 5.915 & $<0.001$ & 0.951 & $<0.001$ \\
Fast Food (g/day) & 5.477 & $<0.001$ & 0.949 & $<0.001$ \\
Processed Food (servings/week) & 9.440 & $<0.001$ & 0.933 & $<0.001$ \\
Non-Processed Food & 12.573 & $<0.001$ & 0.904 & $<0.001$ \\
(servings/week) & 45.522 & $<0.001$ & 0.754 & $<0.001$ \\
Stress Level & 45.515 & $<0.001$ & 0.761 & $<0.001$ \\
Happiness & 39.435 & $<0.001$ & 0.779 & $<0.001$ \\
Problems & & & & \\
\hline & & & &
\end{tabular}

\subsubsection{Model Fitting}

Figure 2 illustrates the model fitting output according to the raw data of SEM. The acceptable model fit values are above 0.9 , and the normed fit index (NFI), comparative fit index (CFI), Tucker 
Lewis index (TLI), incremental fit index (IFI), relative fit index (RTI) and goodness of fit index (GFI) values are all evidently acceptable.

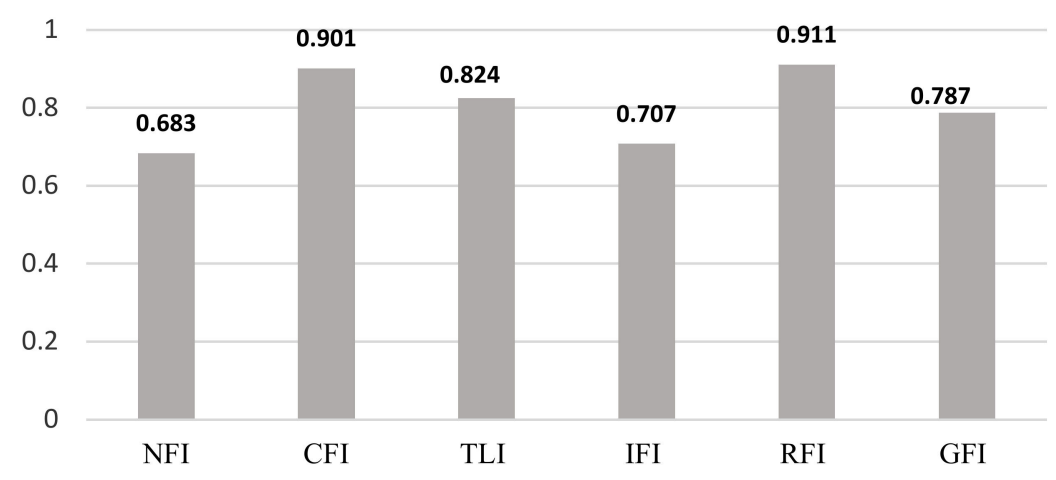

Figure 2. Model fit analysis.

Based on Figure 2, from the four indices, four of them (NFI, TLI, IFI, and GFI) obtain less than 0.9. Therefore, model fitting is not accepted for the raw data. In order to solve this issue, modification indices are used. Modification indices are applied to create alternative models to improve fitting. But, they must be supplemented with sufficient reasons based on theoretical justification [78]. In addition, Silvia et al. [79] suggested that it should be minimized to avoid over-fitting in the modeling analysis. We applied the times' modification indices. Figure 3 shows the model fitting analysis after we applied the first and the second modification indices in our modeling process.

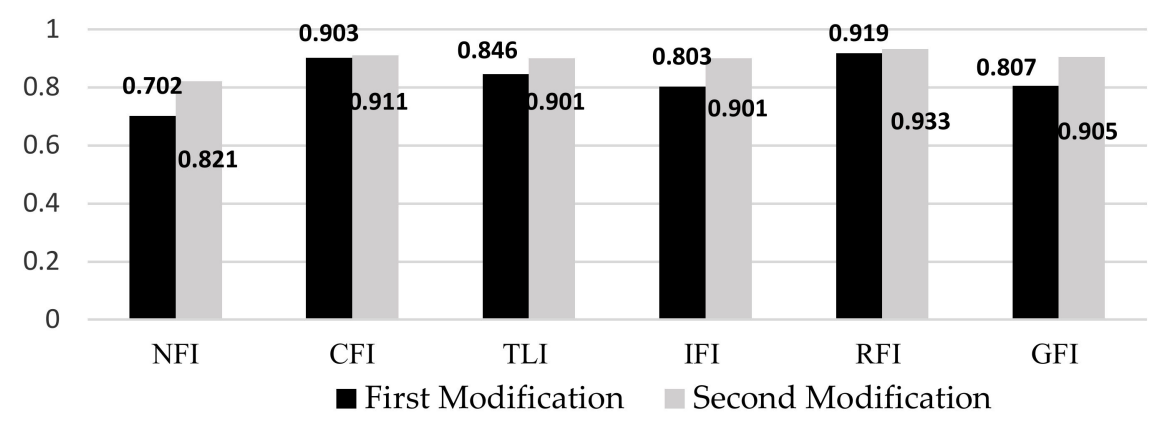

Figure 3. Model fit analysis after modification indices analysis.

\subsection{Comparison Analysis among Different SEM Estimators}

This section presents a comparative analysis of the SEM with maximum likelihood estimator, partial least square in estimating the BMI in the obesity framework. Four indices were used to compare the two prediction methods: coefficient of determination $\left(\mathrm{R}^{2}\right)$, root mean square error (RMSE), mean absolute error (MSE) and mean absolute percentage error (MPE). These are the most common statistical indices for modeling evaluation, and they are clarified by the following equations:

(a) Coefficient of Determination $\left(\mathrm{R}^{2}\right)$

$$
\mathrm{R}^{2}=\frac{\left[\sum_{\mathrm{i}=1}^{\mathrm{n}}\left(\mathrm{y}_{\mathrm{i}}^{\prime}-\overline{\mathrm{y}}_{\mathrm{i}}^{\prime}\right) \cdot\left(\mathrm{y}_{\mathrm{i}}-\overline{\mathrm{y}}_{\mathrm{i}}\right)\right]^{2}}{\sum_{\mathrm{i}=1}^{\mathrm{n}}\left(\mathrm{y}_{\mathrm{i}}^{\prime}-\overline{\mathrm{y}}_{\mathrm{i}}^{\prime}\right) \cdot \sum_{\mathrm{i}=1}^{\mathrm{n}}\left(\mathrm{y}_{\mathrm{i}}-\overline{\mathrm{y}}_{\mathrm{i}}\right)}
$$

(b) Root mean square error (RMSE)

$$
\text { RMSE }=\sqrt[2]{\frac{\sum_{\mathrm{i}=1}^{\mathrm{n}}\left(\mathrm{y}_{\mathrm{i}}^{\prime}-\mathrm{y}_{\mathrm{i}}\right)^{2}}{\mathrm{n}}}
$$


(c) Mean absolute error (MSE)

$$
\text { MSE }=\frac{\sum_{\mathrm{i}=1}^{\mathrm{n}}\left|\mathrm{y}_{\mathrm{i}}^{\prime}-\mathrm{y}_{\mathrm{i}}\right|}{\mathrm{n}}
$$

(d) Mean absolute percentage error (MPE)

$$
\text { MAPE }=\frac{1}{n} \sum_{i=1}^{n}\left|\frac{y_{i}^{\prime}-y_{i}}{y_{i}}\right|
$$

In the formula above, $y_{i}$ is the $\mathrm{i}^{\text {th }}$ actual value of the dependent variable and $y_{i}^{\prime}$ is the $\mathrm{i}^{\text {th }}$ predicted value. Table 7 presents the values of the four performance indices, including $\mathrm{R}^{2}$, RMSE, MSE, and MPE for maximum likelihood, partial least square, and the Bayesian estimators. The $\mathrm{R}^{2}$ value for SEM with the Bayesian estimator is more significant than that for partial least square and maximum likelihood estimators. Moreover, the values of RMSE, MSE, and MPE for the Bayesian estimator are lower than those for the maximum likelihood and partial least square estimators. Therefore, the performance indices for the SEM with the Bayesian estimator indicate a superior estimation compared to SEM with a partial least square estimator or SEM with maximum likelihood estimator.

Table 7. Comparison analysis among different SEM estimators.

\begin{tabular}{ccccc}
\hline & \multicolumn{4}{c}{ Statistical Indices } \\
\hline & $\mathbf{R}^{\mathbf{2}}$ & RMSE & MSE & MPE \\
\hline SEM-Partial Least Square & 0.736 & 4.166 & 0.121 & 0.093 \\
SEM-Maximum Likelihood & 0.781 & 3.151 & 0.109 & 0.059 \\
SEM-Bayesian & 0.823 & 2.118 & 0.089 & 0.039 \\
\hline
\end{tabular}

\subsection{Structural Model}

With the SEM technique, the structural model serves to recognize the hypothesized relationships between the variables that show the links to the presumed model's conception. Figure 4 presents urban and rural structural models.

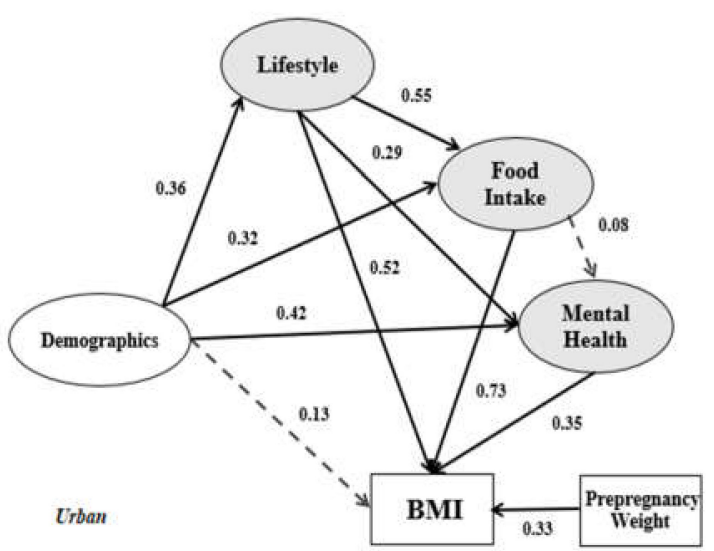

(a)

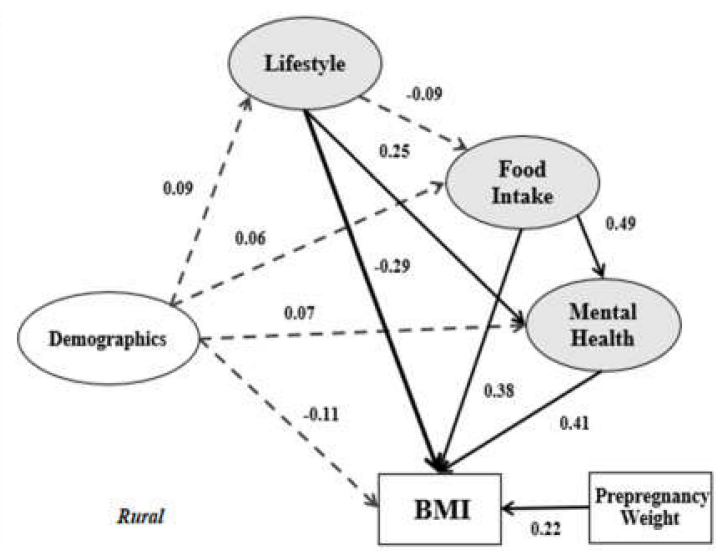

(b)

Figure 4. (a) Urban structural model; (b) Rural structural model.

Figure 4 shows the structural models i.e., (a) urban structural model and (b) rural structural model. From the ten relationships in the urban model, demographic details has a significant impact 
on lifestyle $(\beta=0.36)$, food intake $(\beta=0.32)$ and mental health $(\beta=0.42)$. However, the impact of demographics on these three variables in the rural model is not significant. It is also observed in both models where demographics did not have a significant impact on the dependent variable. It means that demographics do not have a significant direct impact on BMI. In the urban model, demographics have a significant indirect impact on BMI through lifestyle, food intake, and mental health. The lifestyle variable in the urban model has a positive significant relationship with food intake $(\beta=0.55)$, mental health $(\beta=0.29)$ and positive significant impact on BMI $(\beta=0.52)$. It has an indirect impact on BMI through food intake and mental health. In the rural model, lifestyle has a significant impact only on mental health, and there is no indirect impact on BMI. According to the urban and rural models in Figure 4 , the impact of food intake on postpartum women's BMI is significant $(\beta=0.73$ and $\beta=0.38$, respectively). Nonetheless, food intake has a more significant and positive impact on mental health in the rural model compared to the urban model. The indirect impact of food intake on BMI is confirmed in the rural model. As for the last variable, mental health is said to have the same significant impact on BMI in both models.

\subsection{Mediation Analysis}

When a mediator exists between independent and dependent variables, the relations may be characterized as an indirect effect, partial mediation, or full mediation, which are defined as follows (see Figure 5):

- Indirect effect: There is no relation between $\mathrm{X}$ and $\mathrm{Y}$, and both $\mathrm{X} \rightarrow \mathrm{M}, \mathrm{M} \rightarrow \mathrm{Y}$ have a significant relationship.

- Partial mediation: $\mathrm{X} \rightarrow \mathrm{M}, \mathrm{M} \rightarrow \mathrm{Y}$, and $\mathrm{X} \rightarrow \mathrm{Y}$ have a significant relationship.

- Full mediation: $\mathrm{X} \rightarrow \mathrm{M}$ and $\mathrm{M} \rightarrow \mathrm{Y}$ have a significant relationship, and $\mathrm{X} \rightarrow \mathrm{Y}$ has no significant relationship.

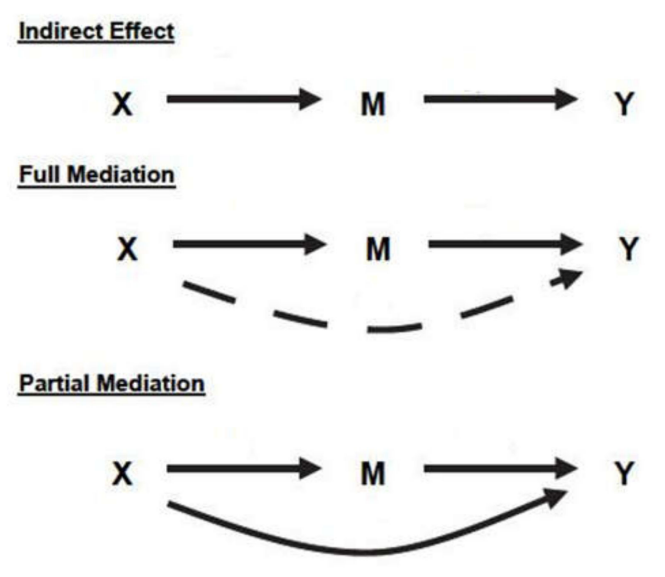

Figure 5. Comparing indirect with full and partial mediation effects.

Based on Figure 4 and Table 8, from both models, the demographics have no significant impact on BMI. Therefore, none of the lifestyle, food intake, and mental health are mediators between the demographics (independent variable) and BMI (dependent variable). However, the indirect effect of Demographics $\rightarrow$ Lifestyle $\rightarrow$ BMI, Demographics $\rightarrow$ Food intake $\rightarrow$ BMI, and Demographics $\rightarrow$ Mental health $\rightarrow$ BMI have significant effects on the urban model. Therefore, the urban model demographics has an indirect effect on BMI through lifestyle, food intake, and mental health. 
Table 8. Mediation analysis of lifestyle, food intake, and mental health between demographics and BMI.

\begin{tabular}{ccccc}
\hline & Direct & Indirect & Total & Result \\
\hline \multicolumn{3}{c}{ Urban } \\
\hline Mediation of lifestyle & 0.13 & $0.36 \times 0.52=0.182 *$ & $0.312 *$ & Indirect effect \\
Mediation of food intake & 0.13 & $0.32 \times 0.73=0.233^{*}$ & $0.363 *$ & Indirect effect \\
Mediation of mental health & 0.13 & $0.42 \times 0.35=0.147^{*}$ & $0.277^{*}$ & Indirect effect \\
\hline \multicolumn{5}{c}{ Rural } \\
Mediation of lifestyle & -0.11 & $0.09 \times-0.29=-0.026$ & -0.136 & - \\
Mediation of food intake & -0.11 & $0.06 \times 0.38=0.022$ & -0.132 & - \\
Mediation of mental health & -0.11 & $0.07 \times 0.41=0.028$ & -0.138 & - \\
\hline
\end{tabular}

In this Table * is representative of significant relationship.

Figure 6 and Table 9 presents the relationship of lifestyle in the research models. Both models show that lifestyle has a significant effect on BMI directly and indirectly through mental health. Therefore, mental health in both models is a mediator between lifestyle and BMI. Only in the urban model, food intake is a mediator between lifestyle and BMI. Therefore, in the urban model, food intake and mental health are mediators between lifestyle and BMI.

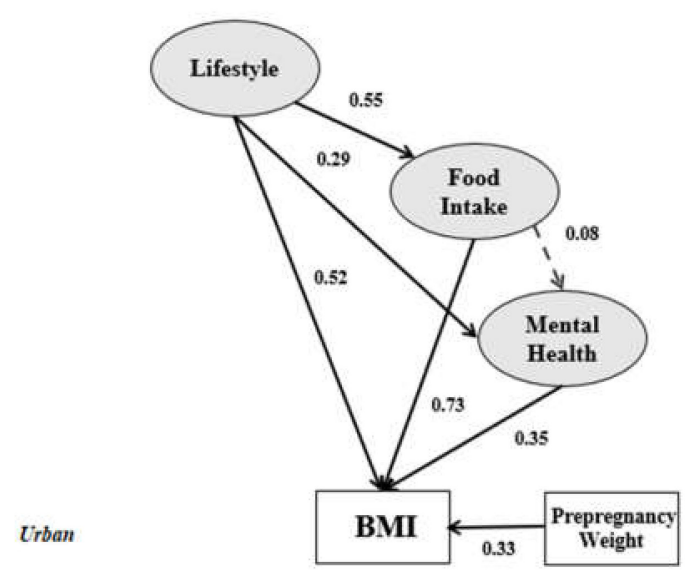

(a)

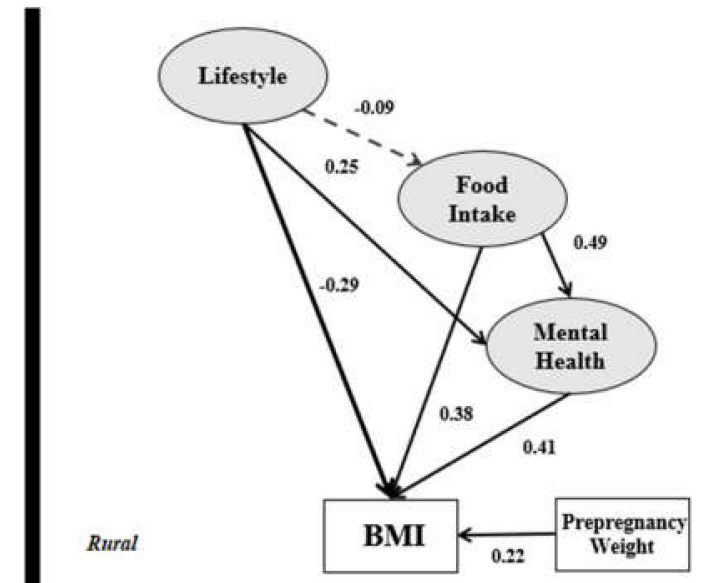

(b)

Figure 6. Lifestyle correlation in the (a) urban and (b) rural research frameworks.

Table 9. Mediation analysis of food intake and mental health between lifestyle and BMI.

\begin{tabular}{ccccc}
\hline & Direct & Indirect & Total & Result \\
\hline \multicolumn{4}{c}{ Urban } \\
\hline Mediation of food intake & $0.52 *$ & $0.55 \times 0.73=0.401 *$ & $0.921 *$ & Mediator (Partial) \\
Mediation of mental health & $0.52 *$ & $0.29 \times 0.35=0.101$ & $0.621^{*}$ & Mediator (Full) \\
\hline & \multicolumn{4}{c}{ Rural } \\
\hline Mediation of food intake & $-0.29 *$ & $-0.09 \times 0.38=0.022$ & $-0.312 *$ & - \\
Mediation of mental health & $-0.29 *$ & $0.25 \times 0.41=0.102 *$ & $-0.392 *$ & Mediator (Partial) \\
\hline
\end{tabular}

In this Table* is representative of significant relationship.

Figure 7 provides a clear view of the food intake variable associated with BMI in the urban and rural models. Food intake does not exhibit the probability of mental health in the urban model, but it correlates with mental health in the rural model $(0.49 \times 0.41=0.200$ and significant). Therefore, specifically for the rural model, mental health is a mediator between food intake and BMI. 


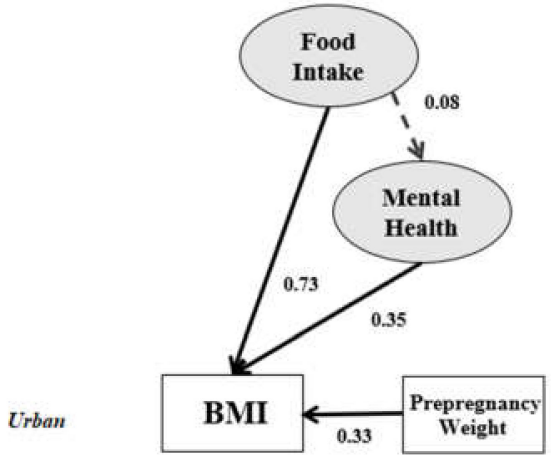

(a)

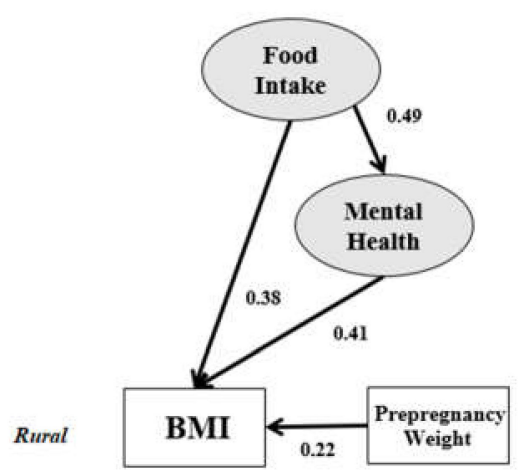

(b)

Figure 7. Impact of food intake in the (a) urban and (b) rural research frameworks.

\subsection{Moderation Analysis}

Chin Test is based on the previous study [80] that suggested the moderation analysis via the $t$-test with the following formula:

$$
t=\frac{\text { Regression Coeficient }_{\text {group } 1}-\text { Regression Coeficient }}{\text { group2 }}
$$

Table 10 presents the $t$-values calculated based on the Chin test, with a significance level of $5 \%$, above the critical $\mathrm{t}$-value with $\mathrm{n}+\mathrm{m}-2$ degrees of freedom for nearly all the correlations (t-value $>1.98)$.

Table 10. Comparison analysis between rural and urban obesity modeling.

\begin{tabular}{lccc}
\hline \multicolumn{1}{c}{ Path } & $\begin{array}{c}\text { Urban } \\
\text { Model }\end{array}$ & $\begin{array}{c}\text { Rural } \\
\text { Model }\end{array}$ & $\begin{array}{c}\text { Chin } \\
\text { Test }\end{array}$ \\
\hline Demographics $\rightarrow$ Lifestyle & 0.39 & 0.11 & $2.36^{*}$ \\
Demographics $\rightarrow$ Food Intake & 0.31 & 0.08 & $1.99 *$ \\
Demographics $\rightarrow$ Mental Health & 0.47 & 0.12 & $3.31^{*}$ \\
Demographics $\rightarrow$ BMI & 0.12 & -0.14 & $2.07^{*}$ \\
Lifestyle $\rightarrow$ Food Intake & 0.55 & -0.02 & $7.21^{*}$ \\
Lifestyle $\rightarrow$ Mental Health & 0.25 & 0.23 & 0.66 \\
Lifestyle $\rightarrow$ BMI & 0.56 & -0.25 & $11.34^{*}$ \\
Food Intake $\rightarrow$ Mental Health & 0.09 & 0.54 & $5.87 *$ \\
Food Intake $\rightarrow$ BMI & 0.66 & 0.34 & $3.09 *$ \\
Mental Health $\rightarrow$ BMI & 0.37 & 0.39 & 0.98 \\
\hline
\end{tabular}

* Has significant difference with 95\% confidence interval. Note: For moderation analysis, both groups (urban and rural) must have the same research variables. In this part of the analysis, we considered all of the research variables in both groups. Therefore, based on the factor loading analysis, we will not eliminate any indicators. In the above sections, we explained the differences among SEM with three types of estimators. There are two more comparison analyses between the SEM with correlation analysis and MANOVA, which we presented in the following two notes. Note 1. Correlation analysis is a common statistical method that some research scholars have been using it to understand the relationship between research variables. However, this method has some weaknesses. Correlation analysis only gives information about the relationship between two variables without involving other variables. Therefore, judging the relationship between two variables based on a correlation analysis would lead to a lack of accuracy. Based on Table 6, the normality of the research variables is rejected. Therefore, for correlation analysis, Spearman correlation was considered. Supplementary Materials Table S1 shows the outputs of the Spearman correlation between all the research variables. Supplementary Materials Table S1 shows the Spearman correlation between BMI and physical activity is equal to $0.019(p$-value $=0.684)$. It means there is no correlation between BMI and physical activity among our sample. However, according to Table 5 , the factor loading of physical activity in lifestyle is equal to 0.77 , and lifestyle has a significant correlation with BMI. 
Note 2. Multivariate analysis of variance (MANOVA) is simply an ANOVA with several dependent variables. Based on Figure 1 we have one dependent variable. For the comparison study between SEM and MANOVA, we considered four models based on BMI level. Model 1 is the representative of modeling based on the underweight group, Model 2 is the representative modeling for the normal group, Model 3 is the representative modeling for the overweight group, and Model 4 is the representative for the obese group.

Table 11 shows the outputs of the R-Square and RMSE of SEM and MANOVA. Based on Table 11, it is illustrated that the R-Squares of SEM for the four models are higher than MANOVA while the RMSE values of the SEM technique are less than MANOVA.

Table 11. Comparison analysis between SEM and MANOVA.

\begin{tabular}{ccccc}
\hline Index & Model 1 & Model 2 & Model 3 & Model 4 \\
\hline R-Square of SEM & 0.762 & 0.812 & 0.834 & 0.711 \\
R-Square of MANOVA & 0.699 & 0.702 & 0.821 & 0.684 \\
RMSE of SEM & 2.113 & 2.765 & 2.097 & 3.621 \\
RMSE of MANOVA & 2.222 & 3.431 & 4.127 & 3.881 \\
\hline
\end{tabular}

\section{Discussion}

This paper aimed to introduce a new framework and examine the relationships between postpartum obesity factors and BMI by applying different SEM estimators. Postpartum women's BMI was the dependent variable and demographics was the main independent variable. Between the demographics and BMI, three latent variables were identified based on previous studies. Hence, an enhanced study model was designed accordingly from previous theories and frameworks of postpartum obesity modelling. The research framework is shown in Figure 1. Two types of data are allotted in the overall dataset, which involves the BMI for urban and rural areas, as per Figure 6. The interrelationships among the demographics, lifestyle, and mental health in the urban model are very strong, as confirmed in a study conducted by Widen et al. [81]. However, these interrelationships in the rural model are weakened by the non-significant impact of demographics on the lifestyle variable.

The impact of demographics on BMI has previously also been confirmed by Hill et al. [82], Ghee [83], and Waring et al. [27]. These preceding studies showed that the indicators of demographics, such as income and working experience, affect the BMI category output, namely being underweight, normal, overweight, and obese. However, the present data analysis in Figure 6 demonstrates that the involvement of demographics (i.e., age, educational background, work experience, and income) on BMI is not significant in both urban and rural models ( $\beta=0.13$ and $\beta=-0.11$, respectively).

Nevertheless, the lifestyle variable in the urban model has been associated with food intake, mental health, and BMI variables. Lifestyle is, therefore, correlated with the dependent variables of this research model. Concerning the factor loading analysis in Table 5, the lifestyle indicator shows that screen time and sleep have the highest factor loadings in the urban areas. In the rural model, the lifestyle variable has a significant impact only on mental health and BMI. Therefore, lifestyle is also directly associated with the BMI variable $(\beta=-0.29)$. The factor analysis in Table 5 highlights that the sleep indicator followed by the work indicator have the highest factor loadings among the lifestyle latent variables. The sleep indicator seems to be very important in the lifestyle factor analysis. A previous study also investigated and found the sleep indicator's effect on BMI [26]. Women typically do less physical activity during pregnancy [20,84]. Still, evidence [4] suggests that light to moderate-intensity physical activity, including aerobic and resistance exercise should be encouraged for 30-60 $\mathrm{min}, 3-5$ times per week without adverse effects in healthy pregnant women.

Many postpartum women often fail to consume a balanced diet, influenced by cultural, psychological, and economic factors. Due to hindrances in healthy eating, especially during the postpartum period, the risk of becoming overweight or obese increases. Previous studies have shown that excessive weight gain in the year following childbirth is caused by maternal obesity. Besides, 
pregnancy with obesity also intensifies food insecurity and lowers the quality of food intake [20]. The path coefficient between food intake and BMI in both models denotes a significant relationship, which has been reported in prior studies [20,85]. Based on the factor analysis (Table 5) for urban areas, the soft drinks indicator has the highest value among the indicators. A prior study also claims that sugar-sweetened beverages (e.g., soft drinks) impact the BMI of postpartum women [31]. Meanwhile, the rural factor analysis for food intake signifies that fruit intake has the highest value. From the highest factor loadings in both models, it is evident that urban postpartum women consume more unhealthy food, and rural postpartum women consume more healthy food.

Referred to the value of $\mathrm{R}^{2}$ in Table 7, we can interpret that SEM with Bayesian estimator of $81.1 \%$ variation in BMI of postpartum women is related to demographics, lifestyle, food intake, and mental health. However, this variation, based on SEM with partial least square estimator and SEM with maximum likelihood estimator, is equal to $70.2 \%$ and $76.8 \%$, respectively. Based on the output of RMSE, MSE, and MPE, the residuals value of the SEM with Bayesian estimator are less than the other two estimators, which means that the predicted values of SEM with Bayesian estimator are closer to the observed value than the maximum likelihood and partial least square. As a result, with higher values of $\mathrm{R}^{2}$ and lower values of MPE, RMSE, and MSE, SEM with the Bayesian estimators have better goodness of fit for the observations.

Figure 4 illustrates a different input-output model structure for urban and rural area data. Nevertheless, some limitations of the current study are as follows:

(1) In previous studies, the parity of mothers [86] was found to be one of the factors that lead to postpartum obesity and should be included in a model. Therefore, the suggestion to study this factor in future research on account of its significance is proposed.

(2) There are other indicators that logically affect postpartum obesity, such as the number of calories consumed per day and the participants' knowledge of calorie intake. However, this article only addressed food intake but not calories.

(3) In this study, the weight, height, and some parts of the food intake of the respondents were self-reported. Based on previous studies had used the same method, we believe the data provided are valid and considerable [87-89]. Other than that, information was collected within $24 \mathrm{~h}$ recall from all participants. To reduce type II error, our data collection team coached participants on how to measure our request variables with high accuracy.

(4) Food Frequency Questionnaire (FFQ), International Physical Activity Questionnaire (IPAQ), Groningen Sleep Quality Scale (GSQS) are the most familiar measurement tools to measure food intake, physical activity, and sleep quality. We had used these questionnaires in our pilot study. However, we have less than $10 \%$ of participants responded to our request, therefore, we chose to use other theories for measuring food intake, physical activity, and sleep quality for this study.

(5) There might be some additional treatments that may have been received by the respondents. Some respondents may also receive treatments from psychiatrists, psychologists, personal trainers, and medicines that may have contributed to the results obtained. Their treatment history might be affecting the BMI among the respondents, so it would be beneficial for future research to correlate these indicators with weight management after pregnancy.

(6) Activity in front of the screen was not included in this study's measurement. This is because a person spending hours in front of the screen reading books, or playing games is not the same as those spending hours on social media. Previous research [90] proves that smartphone addiction influences the evaluation of mental health, i.e., depression. We would suggest that researchers consider this criterion in future research.

(7) Our study is limited in terms of being a cross-sectional survey. As such, it has the deficiency of measuring a single moment, which is not convenient when analyzing variables such as mental health. This is because these variables can be affected by a chronic state of obesity and being in a 
poor family network. To provide more confidence in the accuracy of the SEM output, we suggest pairing the proposed model with longitudinal data.

Consequently, three recommendations are made for practice or policymaking to improve postpartum women's weight and prevent postpartum obesity. First, this study sought to practically attract the attention of health professionals to provide postpartum women affected by obesity with suitable healthcare follow-up. By understanding what postpartum women with overweight or obese feel and think, clinical intervention could help them live a healthier lifestyle. These women would also be more determined to change if the health teams provide a listening, welcoming, and counselling environment. Second, healthcare professionals should disseminate the latest updates on obesity risks more effectively and frequently via all possible social media platforms. In this era of information and communications technology (ICT), social media makes the perfect platform to spread knowledge to people, raising a massive awareness about obesity. Third, policymakers need to strengthen their strategies for obesity prevention by making them more user-friendly to resonate with women's daily routines, especially mothers. Adapting more comfortable and convenient policies may help people change and become healthier.

\section{Conclusions}

Obesity not only burdens healthcare systems globally, but it can also potentially impair national economies. Young and adult women appear to be at increased risk of substantial weight gain. Pregnancy has frequently been cited as a contributor to overweight and obesity problems in women, creating a worldwide public health challenge. Women undergo unpleasant experiences throughout their reproduction cycle, including pregnancy, lactation, and childcare. These may have significant impacts on women's health in terms of parity, obesity, and non-communicable diseases. This article reviewed literature that examines the development of overweight and obesity after pregnancy. It is generally agreed that there is a great probability that high BMI pregnancies carry the risk of experiencing postpartum overweight or obesity. The new framework for postpartum obesity modelling presented in the current study is an improvement from previous studies on food intake, lifestyle, and mental health with a focus on postpartum women's weight.

In this research, we examined three types of SEM estimators. We became aware that SEM also has some advantages in comparing the regression modelling, MANOVA, and Spearman correlation. However, SEM has some limitations in terms of the normality of the research variable, sample size, and some of the variables are not able to be included in the research model.

Supplementary Materials: The supplementary materials are available online at http://www.mdpi.com/1660-4601/ $17 / 14 / 5201 / \mathrm{s} 1$.

Author Contributions: Conceptualization, H.S.J. and N.S.; Methodology, C.W.J.B.W.M.R., H.S.J. and N.S; Supervision, C.W.J.B.W.M.R. and H.S.J.; Writing-original draft, C.W.J.B.W.M.R., H.S.J. and N.S. All authors have read and agreed to the published version of the manuscript.

Funding: This research was supported by the Faculty of Science, University of Malaya, Malaysia (Grant NO: GPF066B-2018). The funder had no role in the study design, data collection and analysis, decision to publish, or article preparation.

Acknowledgments: The authors would like to thank the participants for their cooperation in this research. Immense gratitude to Mohammad Arashi as well for helping with the data collection.

Conflicts of Interest: The authors declare no conflict of interest.

\section{References}

1. The WHO. Obesity and Overweight. 2018. Available online: http://www.who.int/news-room/fact-sheets/ detail/obesity-and-overweight (accessed on 23 October 2018).

2. Dooley, A.A.; Pillai, D.K. Paedatric obesity-related asthma: Disease burden and effects on pulmonary physiology. Paediatr. Respir. Rev. 2020. [CrossRef] 
3. Tan, J.; Ren, Y.; Qi, Y.; Chen, P.; Tang, L.; He, G.; Li, S.; Sun, X.; Liu, X. The pattern of gestational weight gains among Chinese women: A repeated measure analysis. Sci. Rep. 2018, 8, 15865. [CrossRef] [PubMed]

4. Farpour-Lambert, N.J.; Ells, L.J.; de Tejada, B.M.; Scott, C. Obesity and Weight Gain in Pregnancy and Postpartum: An Evidence Review of Lifestyle Interventions to Inform Maternal and Child Health Policies. Front. Endocrinol. 2018, 9. [CrossRef] [PubMed]

5. Van den Akker, K.; Schyns, G.; Jansen, A. Altered appetitive conditioning in overweight and obese women. Behav. Res. Ther. 2017, 99, 78-88. [CrossRef] [PubMed]

6. Woetzel, J.; Dobbs, R.; Manyika, J.; Sawers, C.; Child, P.; Thompson, F. Overcoming Obesity: An Initial Economic Analysis; McKinsey Global Institute: New York, NY, USA, 2014.

7. Leung, S.L.; Barber, J.A.; Burger, A.; Barnes, R.D. Factors associated with healthy and unhealthy workplace eating behaviours in individuals with overweight/obesity with and without binge eating disorder. Obes. Sci. Pract. 2018, 4, 109-118. [CrossRef]

8. Cruz, K.J.C.; de Oliveira, A.R.S.; Morais, J.B.S.; Severo, J.S.; Beserra, J.B.; Santos, L.R.D.; Colli, C.; Freitas, B.D.E.S.D.; Marreiro, D.N. Relationship between magnesium status and cardiovascular risk in obese women. Nutr. Clin. Metab. 2018, 32, 22-26. [CrossRef]

9. Lee, H.; Ahn, R.; Kim, T.H.; Han, E. Impact of Obesity on Employment and Wages among Young Adults: Observational Study with Panel Data. Int. J. Environ. Res. Public Health 2019, 16, 139. [CrossRef]

10. Moussa, H.N.; Alrais, M.A.; Leon, M.G.; Abbas, E.L.; Sibai, B.M. Obesity epidemic: Impact from preconception to postpartum. Future Sci. 2016, 2. [CrossRef]

11. Pendeloski, K.P.T.; Ono, E.; Torloni, M.R.; Mattar, R.; Daher, S. Maternal obesity and inflammatory mediators: A controversial association. Am. J. Reprod. Immunol. 2017, 77. [CrossRef]

12. Neville, C.E.; McKinley, M.C.; Holmes, V.A.; Spence, D.; Woodside, J.V. The relationship between breastfeeding and postpartum weight change-A systematic review and critical evaluation. Int. J. Obes. 2013, 38, 577. [CrossRef]

13. Meng, Y.; Groth, S.W.; Li, D.M. The Association between Obesity-Risk Genes and Gestational Weight Gain Is Modified by Dietary Intake in African American Women. J. Nutr. Metab. 2018. [CrossRef]

14. Miao, M.; Dai, M.; Zhang, Y.; Sun, F.; Guo, X.; Sun, G. Influence of maternal overweight, obesity and gestational weight gain on the perinatal outcomes in women with gestational diabetes mellitus. Sci. Rep. 2017, 7, 305. [CrossRef]

15. Dinsdale, S.; Branch, K.; Cook, L.; Shucksmith, J. “As soon as you've had the baby that's it..." A qualitative study of 24 postnatal women on their experience of maternal obesity care pathways. BMC Public Health 2016, 16, 625. [CrossRef] [PubMed]

16. Hernandez-Higareda, S.; Perez-Perez, O.A.; Balderas-Pena, L.M.A.; Martinez-Herrera, B.E.; Salcedo-Rocha, A.L.; Ramirez-Conchas, R.E. Maternal metabolic diseases related to pre-pregnancy overweight and obesity in mexican women with high risk pregnancy. Cirugia Cirujanos 2017, 85, 292-298. [CrossRef]

17. Bogaerts, A.; De Baetselier, E.; Ameye, L.; Dilles, T.; Van Rompaey, B.; Devlieger, R. Postpartum weight trajectories in overweight and lean women. Midwifery 2017, 49, 134-141. [CrossRef]

18. Butte, N.F.; Garza, C.; Stuff, J.E.; Smith, E.O.; Nichols, B.L. Effect of maternal diet and body composition on lactational performance. Am. J. Clin. Nutr. 1984, 39, 296-306. [CrossRef] [PubMed]

19. Orozco-Muñoz, C.; Cañizares-Luna, O.; Sarasa-Muñoz, N.L. Postpartum Obesity in Cuba: Risk Outweighs Response. Int. J. Cuba. Health Med. 2017, 19, 75.

20. Faria-Schutzer, D.B.; Surita, F.G.; Rodrigues, L.; Turato, E.R. Eating Behaviors in Postpartum: A Qualitative Study of Women with Obesity. Nutrients 2018, 10, 885. [CrossRef]

21. Fadzil, F.; Shamsuddin, K.; Wan Puteh, S.E.; Mohd Tamil, A.; Ahmad, S.; Abdul Hayi, N.S.; Abdul Samad, A.; Ismail, R.; Ahmad Shauki, N.I. Predictors of postpartum weight retention among urban Malaysian mothers: A prospective cohort study. Obes. Res. Clin. Pract. 2018, 12, 493-499. [CrossRef]

22. Alsobayel, H.; Buragadda, S.; Aljuaid, S.; Basamad, L.; Alshehri, S.; Alhenaki, M.; Murayshed, H.; Melam, G.R. Sociodemographic factors associated with postpartum physical activity levels in working women. Women Health 2020, 60, 60-71. [CrossRef]

23. Cherono, R.; Ogada, I.A.; Kimiywe, J. Weight Status at Postpartum: Being Normal Weight Yet Centrally Obese! Food Nutr. Sci. 2019, 10, 1085-1095. [CrossRef] 
24. Cheney, K.; Berkemeier, S.; Sim, K.A.; Gordon, A.; Black, K. Prevalence and predictors of early gestational weight gain associated with obesity risk in a diverse Australian antenatal population: A cross-sectional study. BMC Pregnancy Childbirth 2017, 17, 296. [CrossRef] [PubMed]

25. Garmendia, M.L.; Zamudio, C.; Araya, M.; Kain, J. Association between prepregnancy obesity and metabolic risk in Chilean premenopausal women 10 y postpartum. Nutrition 2017, 38, 20-27. [CrossRef] [PubMed]

26. Wen, S.-Y.; Ko, Y.-L.; Jou, H.-J.; Chien, L.-Y. Sleep quality at 3 months postpartum considering maternal age: A comparative study. Women Birth 2018, 31, e367-e373. [CrossRef] [PubMed]

27. Waring, M.E.; Simas, T.A.M.; Oleski, J.; Xiao, R.S.; Mulcahy, J.A.; May, C.N.; Pagoto, S.L. Feasibility and Acceptability of Delivering a Postpartum Weight Loss Intervention via Facebook: A Pilot Study. J. Nutr. Educ. Behav. 2018, 50, 70-74.E1. [CrossRef]

28. Hegaard, H.K.; Rode, L.; Katballe, M.K.; Langberg, H.; Ottesen, B.; Damm, P. Influence of pre-pregnancy leisure time physical activity on gestational and postpartum weight gain and birth weight-A cohort study. J. Obstet. Gynaecol. 2017, 37, 736-741. [CrossRef]

29. Sanda, B.; Vistad, I.; Sagedal, L.R.; Haakstad, L.A.H.; Lohne-Seiler, H.; Torstveit, M.K. Effect of a prenatal lifestyle intervention on physical activity level in late pregnancy and the first year postpartum. PLoS ONE 2017, 12. [CrossRef]

30. Mukora-Mutseyekwa, F.; Zeeb, H.; Nengomasha, L.; Kofi Adjei, N. Trends in Prevalence and Related Risk Factors of Overweight and Obesity among Women of Reproductive Age in Zimbabwe, 2005-2015. Int. J. Environ. Res. Public Health 2019, 16, 2758. [CrossRef]

31. Kay, M.C.; Wasser, H.; Adair, L.S.; Thompson, A.L.; Siega-Riz, A.M.; Suchindran, C.M.; Bentley, M.E. Consumption of key food groups during the postpartum period in low-income, non-Hispanic black mothers. Appetite 2017, 117, 161-167. [CrossRef]

32. Harris, A.; Chilukuri, N.; West, M.; Henderson, J.; Lawson, S.; Polk, S.; Levine, D.; Bennett, W.L. Obesity-Related Dietary Behaviors among Racially and Ethnically Diverse Pregnant and Postpartum Women. J. Pregnancy 2016. [CrossRef]

33. De Vilhena, E.C.; de Castilho, E.A. Homeopathic Treatment of Overweight and Obesity in Pregnant Women With Mental Disorders: A Double-blind, Controlled Clinical Trial. Altern. Ther. Health Med. 2016, 22, 14-22.

34. Lopuszanska, U.; Skorzynska-Dziduszko, K.; Prendecka, M.; Makara-Studzinska, M. Overweight, obesity and cognitive functions disorders in group of people suffering from mental illness. Psychiatria Polska 2016, 50, 393-406. [CrossRef] [PubMed]

35. Nagl, M.; Lehnig, F.; Stepan, H.; Wagner, B.; Kersting, A. Associations of childhood maltreatment with pre-pregnancy obesity and maternal postpartum mental health: A cross-sectional study. BMC Pregnancy Childbirth 2017, 17. [CrossRef] [PubMed]

36. Teo, C.; Chia, A.-R.; Colega, M.T.; Chen, L.-W.; Fok, D.; Pang, W.W.; Godfrey, K.M.; Tan, K.H.; Yap, F.; Shek, L.P.-C. Prospective Associations of Maternal Dietary Patterns and Postpartum Mental Health in a Multi-Ethnic Asian Cohort: The Growing up in Singapore towards Healthy Outcomes (GUSTO) Study. Nutrients 2018, 10, 299. [CrossRef]

37. Durham, H.A. Food Habits and Choices, Physical Activity, and Breastfeeding Among Overweight and Obese Postpartum Women; The University of North Carolina at Greensboro: Greensboro, NC, USA, 2008; ISBN 054960720X.

38. Althuizen, E.; van Poppel, M.N.; de Vries, J.H.; Seidell, J.C.; van Mechelen, W. Postpartum behaviour as predictor of weight change from before pregnancy to one year postpartum. BMC Public Health 2011, 11, 165. [CrossRef]

39. Kit, A.; Ohnishi, M. An evaluation of strategies to promote health to tackle food restriction in postpartum women in Lao People's Democratic Republic. Health Research 2017, 29, 59-66.

40. Huang, H.; Radzi, W.M.; Salarzadeh Jenatabadi, H. Family Environment and Childhood Obesity: A New Framework with Structural Equation Modeling. Int. J. Environ. Res. Public Health 2017, 14, 181. [CrossRef]

41. Wan Mohamed Radzi, C.W.J.; Salarzadeh Jenatabadi, H.; Alanzi, A.R.; Mokhtar, M.I.; Mamat, M.Z.; Abdullah, N.A. Analysis of Obesity among Malaysian University Students: A Combination Study with the Application of Bayesian Structural Equation Modelling and Pearson Correlation. Int. J. Environ. Res. Public Health 2019, 16, 492. [CrossRef] 
42. Endres, L.K.; Straub, H.; McKinney, C.; Plunkett, B.; Minkovitz, C.S.; Schetter, C.D.; Ramey, S.; Wang, C.; Hobel, C.; Raju, T.; et al. Postpartum weight retention risk factors and relationship to obesity at one year. Obstet. Gynecol. 2015, 125, 144. [CrossRef]

43. Incollingo Rodriguez, A.C.; Dunkel Schetter, C.; Tomiyama, A.J.J.S. Weight stigma among pregnant and postpartum women: A new context of stigmatization. Stigma Health 2019, 5, 209-216. [CrossRef]

44. Jenatabadi, H.S.; Moghavvemi, S.; Mohamed, C.W.J.B.W.; Babashamsi, P.; Arashi, M. Testing students'e-learning via Facebook through Bayesian structural equation modeling. PLoS ONE 2017, 12, e0182311.

45. Cole, D.A.; Ciesla, J.A.; Steiger, J.H. The insidious effects of failing to include design-driven correlated residuals in latent-variable covariance structure analysis. Psychol. Methods 2007, 12, 381. [CrossRef] [PubMed]

46. Kolenikov, S. Biases of parameter estimates in misspecified structural equation models. Sociol. Methodol. 2011, 41, 119-157. [CrossRef]

47. Roberts, N.; Thatcher, J.B.; Grover, V. Advancing operations management theory using exploratory structural equation modelling techniques. Int. J. Prod. Res. 2010, 48, 4329-4353. [CrossRef]

48. Wong, M.S.; Showell, N.N.; Bleich, S.N.; Gudzune, K.A.; Chan, K.S. The association between parent-reported provider communication quality and child obesity status: Variation by parent obesity and child race/ethnicity. Patient Educ. Couns. 2017, 100, 1588-1597. [CrossRef]

49. R Core Team. R Language Definition; R Foundation for Statistical Computing: Vienna, Austria, 2000.

50. R Core Team. R: A Language and Environment for Statistical Computing; R Foundation for Statistical Computing: Vienna, Austria, 2013.

51. Rosseel, Y.; Joss, J. Lavaan: An R package for structural equation modeling and more. Version 0.5-12 (BETA). J. Stat. Softw. 2012, 48, 1-36. [CrossRef]

52. Neale, M.C.; Hunter, M.D.; Pritikin, J.N.; Zahery, M.; Brick, T.R.; Kirkpatrick, R.M.; Estabrook, R.; Bates, T.C.; Maes, H.H.; Boker, S.M. OpenMx 2.0: Extended structural equation and statistical modeling. Psychometrika 2016, 81, 535-549. [CrossRef]

53. Byrne, B.M. Structural Equation Modeling with Amos: Basic Concepts, Applications, and Programming; Routledge: London, UK, 2016; ISBN 131763313X.

54. Molenaar, P.C. Review of Multivariate Analysis With LISREL; Taylor \& Francis: Milton Park, UK, 2019.

55. Muthén, L.; Muthén, B. Mplus. The Comprehensive Modelling Program for Applied Researchers: User's Guide; Muthén \& Muthén: Los Angeles, CA, USA, 2018.

56. Hair, J.; Black, W.; Babin, B.; Anderson, R. Multivariate Data Analysis; Pearson New International Edition; Pearson/Prentice Hall: New Jersey, NJ, USA, 2014.

57. Zielinski, R.; Low, L.K.; Smith, A.R.; Miller, J.M. Body after baby: A pilot survey of genital body image and sexual esteem following vaginal birth. Int. J. Womens Health 2017, 9, 189. [CrossRef]

58. Plunkett, C.; Peters, S.; Wieck, A.; Wittkowski, A. A qualitative investigation in the role of the baby in recovery from postpartum psychosis. Clin. Psychol. Psychother. 2017, 24, 1099-1108. [CrossRef]

59. Mullen, M.R.; Milne, G.R.; Doney, P.M. An International Marketing Application Of Outlier Analysis For Structural Equations-A Methodological Note. J. Int. Mark. 1995, 3, 45-62. [CrossRef]

60. Rezaei, N.; Azadi, A.; Zargousi, R.; Sadoughi, Z.; Tavalaee, Z.; Rezayati, M. Maternal health-related quality of life and its predicting factors in the postpartum period in Iran. Scientifica 2016, 2016, 8542147. [CrossRef]

61. Lau, Y.; Htun, T.P.; Lim, P.I.; Ho-Lim, S.S.T.; Chi, C.; Tsai, C.; Ong, K.W.; Klainin-Yobas, P. Breastfeeding attitude, health-related quality of life and maternal obesity among multi-ethnic pregnant women: A multi-group structural equation approach. Int. J. Nurs. Stud. 2017, 67, 71-82. [CrossRef] [PubMed]

62. Yanuar, F.; Ibrahim, K.; Jemain, A.A. Bayesian structural equation modeling for the health index. J. Appl. Stat. 2013, 40, 1254-1269. [CrossRef]

63. Kac, G.; Benicio, M.H.; Velasquez-Meléndez, G.; Valente, J.G. Nine months postpartum weight retention predictors for Brazilian women. Public Health Nutr. 2004, 7, 621-628. [CrossRef] [PubMed]

64. Hoyle, R.; Panter, A. Writing about structural equation modeling. In Structural Equation Modelling; Hoyle, R.H., Ed.; Sage: Thousand Oaks, CA, USA, 1995.

65. Nakayama, K.; Yamaguchi, K.; Maruyama, S.; Morimoto, K. The relationship of lifestyle factors, personal character, and mental health status of employees of a major Japanese electrical manufacturer. Environ. Health Prev. Med. 2001, 5, 144-149. [CrossRef] [PubMed] 
66. Melzer, K.; Schutz, Y. Pre-pregnancy and pregnancy predictors of obesity. Int. J. Obes. 2010, 34, S44. [CrossRef]

67. Khajeheian, D.; Colabi, A.M.; Shah, N.; Radzi, C.; Jenatabadi, H.S. Effect of Social Media on Child Obesity: Application of Structural Equation Modeling with the Taguchi Method. Int. J. Environ. Res. Public Health 2018, 15, 1343. [CrossRef]

68. Kolovos, S.; Jimenez-Moreno, A.C.; Pinedo-Villanueva, R.; Cassidy, S.; Zavala, G.A. Association of sleep, screen time and physical activity with overweight and obesity in Mexico. Eating Weight Disord. Stud. Anorex. Bulim. Obes. 2019, 1-11. [CrossRef] [PubMed]

69. De Pinho, M.G.M.; Adami, F.; Benedet, J.; de Vasconcelos, F.D.G. Association between screen time and dietary patterns and overweight/obesity among adolescents. Revista Nutrição 2017, 30, 377-389. [CrossRef]

70. Gong, Q.H.; Li, H.; Zhang, X.H.; Zhang, T.; Cui, J.; Xu, G.Z. Associations between sleep duration and physical activity and dietary behaviors in Chinese adolescents: Results from the Youth Behavioral Risk Factor Surveys of 2015. Sleep Med. 2017, 37, 168-173. [CrossRef]

71. Kröller, K.; Warschburger, P. Maternal feeding strategies and child's food intake: Considering weight and demographic influences using structural equation modeling. Int. J. Behav. Nutr. Phys. Act. 2009, 6, 78. [CrossRef]

72. Mendonça, R.D.D.; Pimenta, A.M.; Gea, A.; de la Fuente-Arrillaga, C.; Martinez-Gonzalez, M.A.; Lopes AC, S.; Bes-Rastrollo, M. Ultraprocessed food consumption and risk of overweight and obesity: The University of Navarra Follow-Up (SUN) cohort study. Am. J. Clin. Nutr. 2016, 104, 1433-1440. [CrossRef]

73. Boardman, J.D. Stress and physical health: The role of neighborhoods as mediating and moderating mechanisms. Soc. Sci. Med. 2004, 58, 2473-2483. [CrossRef] [PubMed]

74. Eum, M.-J.; Jung, H.-S. Association between Occupational Characteristics and Overweight and Obesity among Working Korean Women: The 2010-2015 Korea National Health and Nutrition Examination Survey. Int. J. Environ. Res. Public Health 2020, 17, 1585. [CrossRef] [PubMed]

75. Chan, R.S.; Woo, J. Prevention of overweight and obesity: How effective is the current public health approach. Int. J. Environ. Res. Public Health 2010, 7, 765-783. [CrossRef] [PubMed]

76. Bollen, K.A. Latent variables in psychology and the social sciences. Annu. Rev. Psychol. 2002, 53, 605-634. [CrossRef]

77. Fornell, C.; Larcker, D.F. Evaluating structural equation models with unobservable variables and measurement error. J. Market. Res. 1981, 18, 39-50. [CrossRef]

78. Garson, G. Structural Equation Modeling; Statistical Associates Publishers: Asheboro, NC, USA, 2007.

79. Silvia, E.S.M.; MacCallum, R.C. Some factors affecting the success of specification searches in covariance structure modeling. Multivar. Behav. Res. 1988, 23, 297-326. [CrossRef]

80. Chin, W.W.; Multi-Group Analysis with PLS. Frequently Asked Questions-Partial Least Squares \& PLS-Graph. 2004. Available online: https://www.researchgate.net/publication/258847316 (accessed on 23 October 2018).

81. Widen, E.M.; Whyatt, R.M.; Hoepner, L.A.; Ramirez-Carvey, J.; Oberfield, S.E.; Hassoun, A.; Perera, F.P.; Gallagher, D.; Rundle, A.G. Excessive gestational weight gain is associated with long-term body fat and weight retention at $7 \mathrm{y}$ postpartum in African American and Dominican mothers with underweight, normal, and overweight prepregnancy BMI. Am. J. Clin. Nutr. 2015, 102, 1460-1467. [CrossRef]

82. Hill, B.; McPhie, S.; Skouteris, H. The Role of Parity in Gestational Weight Gain and Postpartum Weight Retention. Womens Health Issues 2016, 26, 123-129. [CrossRef]

83. Ghee, L.K. A Review of Adult Obesity Research in Malaysia. Med. J. Malays. 2016, 71, 7.

84. Guardino, C.M.; Hobel, C.J.; Shalowitz, M.U.; Ramey, S.L.; Schetter, C.D. Community Child Health Network. Psychosocial and demographic predictors of postpartum physical activity. J. Behav. Med. 2018, 41, 668-679. [CrossRef] [PubMed]

85. Davis, J.N.; Shearrer, G.E.; Tao, W.; Hurston, S.R.; Gunderson, E.P. Dietary variables associated with substantial postpartum weight retention at 1-year among women with GDM pregnancy. BMC Obesity. 2017, 4, 31. [CrossRef]

86. Wilcox, S.; Liu, J.; Addy, C.L.; Turner-McGrievy, G.; Burgis, J.T.; Wingard, E.; Dahl, A.A.; Whitaker, K.M.; Schneider, L.; Boutté, A.K. A randomized controlled trial to prevent excessive gestational weight gain and promote postpartum weight loss in overweight and obese women: Health In Pregnancy and Postpartum (HIPP). Contemp. Clin. Trials 2018, 66, 51-63. [CrossRef] [PubMed] 
87. Croghan, I.T.; Huber, J.M.; Hurt, R.T.; Schroeder, D.R.; Wieland, M.L.; Rutten, L.J.; Ebbert, J.O. Patient perception matters in weight management. Prim. Health Care Res. Dev. 2018, 19, 197-204. [CrossRef]

88. Leung, M.Y.M.; Carlsson, N.P.; Colditz, G.A.; Chang, S.-H. The Burden of Obesity on Diabetes in the United States: Medical Expenditure Panel Survey, 2008 to 2012. Value Health 2017, 20, 77-84. [CrossRef]

89. Ievers-Landis, C.E.; Dykstra, C.; Uli, N.; O'Riordan, M.A. Weight-Related Teasing of Adolescents Who Are Primarily Obese: Roles of Sociocultural Attitudes Towards Appearance and Physical Activity Self-Efficacy. Int. J. Environ. Res. Public Health 2019, 16, 1540. [CrossRef]

90. Kim, E.; Cho, I.; Kim, E.J. Structural Equation Model of Smartphone Addiction Based on Adult Attachment Theory: Mediating Effects of Loneliness and Depression. Asian Nurs. Res. 2017, 11, 92-97. [CrossRef]

(C) 2020 by the authors. Licensee MDPI, Basel, Switzerland. This article is an open access article distributed under the terms and conditions of the Creative Commons Attribution (CC BY) license (http://creativecommons.org/licenses/by/4.0/). 